\title{
The supplemental value of mammographic screening over breast MRI alone in BRCA2 mutation carriers
}

\author{
Inge-Marie Obdeijn ${ }^{1} \cdot$ Ritse M. Mann ${ }^{2,3}$. Claudette C. E. Loo ${ }^{3} \cdot$ Marc Lobbes $^{4,5,6} \cdot$ Eleonora M. C. Voormolen ${ }^{7}$. \\ Carolien H. M. van Deurzen ${ }^{8}$. Geertruida de Bock ${ }^{9} \cdot$ Hereditary Breast Ovarian Cancer Research Group Netherlands \\ $\left(\right.$ HEBON) $\cdot$ Maartje J. Hooning ${ }^{10}$
}

Received: 12 December 2019 / Accepted: 10 April 2020 / Published online: 24 April 2020

(c) The Author(s) 2020

\begin{abstract}
Purpose BRCA2 mutation carriers are offered annual breast screening with MRI and mammography. The aim of this study was to investigate the supplemental value of mammographic screening over MRI screening alone.

Methods In this multicenter study, proven BRCA2 mutation carriers, who developed breast cancer during screening using both digital mammography and state-of-art breast MRI, were identified. Clinical data were reviewed to classify cases in screen-detected and interval cancers. Imaging was reviewed to assess the diagnostic value of mammography and MRI, using the Breast Imaging and Data System (BI-RADS) classification allocated at the time of diagnosis.

Results From January 2003 till March 2019, 62 invasive breast cancers and 23 ductal carcinomas in situ were diagnosed in 83 BRCA2 mutation carriers under surveillance. Overall screening sensitivity was $95.2 \%$ (81/85). Four interval cancers occurred (4.7\% (4/85)). MRI detected 73 of 85 breast cancers (sensitivity 85.8\%) and 42 mammography (sensitivity 49.9\%) $(p<0.001)$.

Eight mammography-only lesions occurred. In 1 of 17 women younger than 40 years, a 6-mm grade 3 DCIS, retrospectively visible on MRI, was detected with mammography only in a 38-year-old woman. The other 7 mammography-only breast cancers were diagnosed in women aged 50 years and older, increasing sensitivity in this subgroup from $79.5 \%$ (35/44) to 95.5\% (42/44) $(p \leq 0.001)$.

Conclusions In BRCA2 mutation carriers younger than 40 years, the benefit of mammographic screening over MRI was very small. In carriers of 50 years and older, mammographic screening contributed significantly. Hence, we propose to postpone mammographic screening in BRCA2 mutation carriers to at least age 40.
\end{abstract}

Keywords BRCA mutation carriers $\cdot$ Screening $\cdot$ MRI $\cdot$ Mammography

Inge-Marie Obdeijn

a.obdeijn@erasmusmc.nl

1 Department of Radiology and Nuclear Medicine, Erasmus University Medical Center, Rotterdam, The Netherlands

2 Department of Radiology and Nuclear Medicine, Radboud University Medical Center, Nijmegen, The Netherlands

3 Department of Radiology, The Netherlands Cancer Institute, Amsterdam, The Netherlands

4 Department of Medical Imaging, Zuyderland Medical Center, Sittard-Geleen, The Netherlands

5 Department of Radiology and Nuclear Medicine, University Medical Center, Maastricht, The Netherlands
6 GROW School for Oncology and Developmental Biology, Maastricht University, Maastricht, The Netherlands

7 Department of Radiology and Nuclear Medicine, Leiden University Medical Center, Leiden, The Netherlands

8 Department of Pathology, Erasmus University Medical Center, Rotterdam, The Netherlands

9 Department of Epidemiology, University Medical Center, Groningen, The Netherlands

10 Department of Medical Oncology, Erasmus MC Cancer Institute, Rotterdam, The Netherlands 


$\begin{array}{ll}\begin{array}{l}\text { Abbreviations } \\ \text { BI-RADS }\end{array} & \begin{array}{l}\text { Breast Imaging Reporting and } \\ \text { Data System } \\ \text { Ductal carcinoma in situ } \\ \text { DCIS }\end{array} \\ \text { HER2 } & \begin{array}{l}\text { Human epidermal growth fac- } \\ \text { tor receptor 2 } \\ \text { Invasive lobular carcinoma } \\ \text { Invasive carcinoma no special } \\ \text { type }\end{array} \\ \text { Invasive carcinoma NST } & \begin{array}{l}\text { Hereditary Breast and Ovar- } \\ \text { ian Cancer Research Group } \\ \text { Netherlands } \\ \text { HEBON }\end{array} \\ \text { Magnetic Resonance Imaging }\end{array}$

\section{Introduction}

Women with a BRCA1 or BRCA 2 mutation have a strongly elevated risk of developing breast cancer [1]. Therefore, annual screening with MRI and mammography starting at young age is advised for women who do not opt for bilateral prophylactic mastectomy, though the optimal screening regimen is not set yet.

In women with a high familial or genetic risk, breast MRI was originally introduced as an adjunct to mammographic screening. However, increasing breast MR expertise and technologic advances over the years have made that breast MR nowadays outperforms mammography in the early detection of invasive breast cancer as well as in the detection of ductal carcinoma in situ (DCIS) [2]. Recent studies demonstrate that, especially in BRCA1 mutation carriers under the age of 40 , there is little benefit of mammographic screening when MRI screening is also performed [3-5]. Furthermore, the exposure to low-dose ionizing radiation as from annual mammographic screening might be more harmful in BRCA mutation carriers. The BRCA gene is involved in the pathway of repair of DNA double strand breaks. In BRCA gene mutation carriers, the impaired function of this pathway may lead to a higher risk of radiation-induced breast cancer [6-8].

As a consequence, in 2018, the Dutch screening guidelines were modified for BRCA1 mutation carriers, nowadays starting with supplemental biennial mammography only from the age of 40 [9].

From the point of breast cancer risk and radiation sensitivity, it would be reasonable to screen BRCA1 and BRCA2 mutation carriers according to the same protocol. However, characteristics of cancers detected in BRCA2 carriers differ significantly from those detected in BRCA1 carriers. While BRCA1 carriers predominantly present with highgrade hormone receptor-negative invasive breast cancer, BRCA2 mutation carriers have more luminal breast cancers and a higher proportion of DCIS, sometimes only detected as mammographic calcifications [10-12]. Consequently, in BRCA2 carriers, supplemental annual mammography from the age of 30 is still regarded as the standard of care.

The aim of this study was to assess whether this bi-modal screening protocol (i.e., with digital mammography from age 30 and state-of-art MRI) is still appropriate in BRCA2 mutation carriers. For this, we evaluated the mode of detection in BRCA2 mutation carriers who developed breast cancer while under surveillance.

\section{Patients and methods}

\section{Patients}

In this retrospective study, we included women with a proven BRCA2 mutation who developed breast cancer during surveillance with digital mammography and breast MRI in one of the five participating Dutch university hospitals (Erasmus University Medical Center Rotterdam, Radboud University Medical Center Nijmegen, Maastricht University Medical Center, University Medical Center Leiden, and University Medical Center Groningen) or in the Netherlands Cancer Institute in Amsterdam. We included consecutive series of BRCA2 breast cancer cases provided by the databases of the family breast cancer clinics of Erasmus University Medical Center Rotterdam and Radboud University Medical Center Nijmegen. For the other centers, we included BRCA2 breast cancer cases provided by the collaborative group on Hereditary Breast and Ovarian Cancer in The Netherlands (HEBON) [13].

Inclusion started after introduction of digital mammography which was between January 2003 (Radboud University Medical Center Nijmegen) and September 2006 (Erasmus University Medical Center Rotterdam). The inclusion period ended in March 30, 2019.

All BRCA2 breast cancer patients provided written informed consent.

Women in whom a BRCA2 mutation was determined after breast cancer diagnosis and BRCA2 mutation carriers with breast cancer detected in specimen from prophylactic mastectomy were excluded from the analysis. We also excluded women in whom only one of the screening methods was used.

Women with a prior history of breast cancer were included.

\section{Methods}

\section{Age}

We divided the women in two age groups: women diagnosed with breast cancer before age 40 and women diagnosed with 
breast cancer at age 40 and older. We chose this age limit for two reasons. Firstly, previous research in women at increased risk showed a very low added value of mammography in the screening of women under 40 years of age, albeit series were too small to provide specific information for women with BRCA2 mutations. Secondly, the breast cancer risk from low-dose ionizing radiation as from annual mammographic screening is strongly dependent on age at exposure with higher risks at younger ages $[5,14,15]$.

\section{Breast MRI}

According to the Dutch guidelines [9], women with a proven BRCA2 mutation were offered annual breast MRI screening from age 25 till age 60 and annual mammographic screening starting at age 30 . After age 60 , breast cancer screening is continued with annual mammography, or, in case of dense breast tissue, with annual screening alternating mammography and MRI.

Breast MRI was performed in each center using local protocols that all met the requirements of currently accepted international guidelines [16], including at least three highresolution T1-weighted acquisitions obtained before, early (90s), and late after (5-7 min) contrast administration. Dedicated analysis software (allowing for the creation of maximum intensity projections, signal intensity versus time curves, and color-coded overlays of enhancement patterns) and MR-guided biopsy tools were available in all centers. All centers had extensive experience with screening of women with familial or genetic predisposition for breast cancer.

\section{Data collection}

The images and related reports of all patients at the time of diagnosis were reviewed by one or two of the dedicated breast radiologists (IMO, RM, CL, ML, NV) in order to assess whether the breast cancers were screen-detected or interval cancers and whether the cancers were visible on mammography and MRI. One radiologist (IMO) reviewed nearly all cases. The mammograms and breast MRI examinations were reported at the time of diagnosis according to the Breast Imaging Reporting and Data System (BI-RADS) [17]. The BI-RADS classifications (both for mammography and MRI) allocated at the time of diagnosis were used for this evaluation. BI-RADS classifications $0,3,4$, and 5 were defined as positive findings because additional work-up was indicated.

A screen-detected breast cancer was defined as a breast cancer found during a screening round by breast MRI and/ or mammography. If a breast cancer was identified clinically (became palpable or caused other symptoms) in between two screening rounds, it was considered an interval cancer.
The pathology reports were evaluated for tumor characteristics. In women who underwent primary surgical treatment, the largest diameter of the tumor as mentioned in the pathology report was recorded to indicate size. In case of multifocal or multicentric disease, the size of the largest cancer was registered. In patients treated with neoadjuvant chemotherapy, the largest diameter measured on the pre-therapeutic MRI was recorded as the size of the breast cancer.

\section{Statistical analysis}

Sensitivity for both screening modalities (breast MRI and mammography) was assessed separately. For the comparison of the screening modalities, we used the data of patients for whom results were available for both modalities at the time of diagnosis. The differences in sensitivity between the two were tested by a McNemar's test for paired proportions.

We also compared sensitivity for breast MRI and mammography separately for the two age groups defined above (women diagnosed before age 40 and women diagnosed at age 40 years and older). The differences in sensitivity between age groups were tested using Fisher's exact test.

A two-sided $p$ value of lower than 0.05 was regarded as statistically significant. Statistical analyses were performed using STATA (STATA version 15.1).

\section{Results}

From January 2003 to March 2019, 83 BRCA2 mutation carriers were diagnosed with 85 breast cancers while under surveillance with both MRI and digital mammography. In the majority of cases (in 75 of 85 cases), MRI and mammography were performed simultaneously or within a short period of time. One woman presented with a synchronous contralateral breast cancer, another woman had a metachronous contralateral breast cancer. Mean age at diagnosis was 49.3 years (range 27-70); 17 breast cancers were diagnosed before age $40(20.0 \%)$.

Sixty-two invasive breast cancers with a mean size of $10.1 \mathrm{~mm}$ (range 3-27 mm) and 23 DCIS lesions were detected. Tumor characteristics can be found in Table 1 . The majority, $68.2 \%$ (58/85) of breast cancers, was detected in an early stage (DCIS or invasive breast cancer $\leq 10 \mathrm{~mm}$ ). Lymph node status was determined to be positive in 12 of 61 women in whom at least a sentinel lymph node biopsy was performed (19.7\%).

Overall, 81 out of 85 breast cancers were screendetected, resulting in an overall screening sensitivity of $95.2 \%$ (81/85). Four interval cancers occurred $(4.7 \%$ $(4 / 85))$ in women aged $39,42,50$, and 51 years with sizes of, respectively, 15, 12, 17, and $19 \mathrm{~mm}$. Based upon the 
Table 1 Tumor characteristics of 85 breast cancers

\begin{tabular}{|c|c|}
\hline Histologic type & Number \\
\hline \multirow[t]{4}{*}{ DCIS $n=23(27.1 \%)$} & Histological grade DCIS \\
\hline & Grade 10 \\
\hline & Grade 212 \\
\hline & Grade 311 \\
\hline \multirow{5}{*}{$\begin{array}{l}\text { Invasive breast cancer } n=62(72.9 \%) \\
\text { (Invasive breast cancer with DCIS component } n=25)\end{array}$} & Histology-invasive breast cancer \\
\hline & $\begin{array}{l}\text { Invasive breast cancer no special type } 54 \\
\text { Invasive lobular carcinoma } 6 \\
\text { Other } 2\end{array}$ \\
\hline & $\begin{array}{l}\text { Histological grade invasive breast cancer } \\
\text { Bloom and Richardson Grade } 17 \\
\text { Bloom and Richardson Grade } 230 \\
\text { Bloom and Richardson Grade } 325\end{array}$ \\
\hline & $\begin{array}{l}\text { Size invasive breast cancer } \\
\leq 10 \mathrm{~mm} 35(56.5 \%) \\
>10 \leq 20 \mathrm{~mm} 25(40.3 \%) \\
>20 \mathrm{~mm} 2(3.2 \%)\end{array}$ \\
\hline & $\begin{array}{l}\text { Receptor status invasive breast cancer } \\
\quad n=59^{*} \\
\text { ER+ and/or PR+, HER2- } 42(71.2 \%) \\
\text { ER+, PR+, HER2+ } 3(5.1 \%) \\
\text { ER-, PR-, HER } 2+3(5.1 \%) \\
\text { ER+, PR_, HER2+ } 1(1.7 \%) \\
\text { Triple- } 10(16.9 \%)\end{array}$ \\
\hline $\begin{array}{l}\text { Nodal status } \\
n=61 * * *\end{array}$ & $\begin{array}{l}\mathrm{N}+19.7 \% * *(12 / 61) \\
\mathrm{N}-80.3 \%(49 / 61)\end{array}$ \\
\hline
\end{tabular}

DCIS ductal carcinoma in situ, HER2 human epidermal growth factor receptor 2

*Her2 status not available in 3 patients

**Including 4 cases with micrometastases

*** Nodal status unknown in one patient with invasive breast cancer re-evaluation of the imaging examinations, two of them were retrospectively visible on MRI. Three of 4 interval cancers were grade 3 triple-negative breast cancer.

MRI detected 73 of 85 breast cancers (sensitivity $85.8 \%$ ) and mammography 42 (sensitivity $49.9 \%$ ) ( $p$ value $<0.001)$. For invasive breast cancer, MRI performed significantly better than mammography (sensitivity, respectively, $90.3 \%$ (56/62) versus $43.5 \%$ (27/62), $(p<0.001))$. For the detection of DCIS, the difference was not statistically significant (sensitivity, respectively, 73.9\% $(17 / 23)$ and $65.2 \%(15 / 23)(p=0.791))$.

The screening sensitivity of the combination of imaging modalities, and the screening sensitivity of breast MRI and mammography separately, was also determined for the pre-defined age groups (Table 2).

Thirty-nine breast cancers were detected by MRI only $(45.8 \%(39 / 85))$ and 8 by mammography only $(9.4 \%(8 / 85)$ (Table 3)). It should be noted that only two of the cancers detected with mammography only were invasive. One of the mammography-only breast cancers was diagnosed before age 40. It concerned a $6 \mathrm{~mm}$ DCIS grade 3 in a 38-year-old woman, retrospectively also visible on MRI.
The other 7 mammography-only breast cancers were diagnosed in women aged 50 years and older (Table 3 and Fig. 1). This subgroup consisted of 42 women with 44 breast cancers of which 35 were correctly depicted by MRI (sensitivity 79.5\% (35/42)). Decombination of MRI and mammography increased the screening sensitivity in this subgroup to $95.5 \%(42 / 44)$.

No mammography-only breast cancers occurred in the subgroup of 24 women diagnosed with breast cancer between age 40 and 49 (Fig. 1).

\section{Discussion}

In this multicenter study, the screening results in BRCA2 mutation carriers showed a high screening sensitivity of $95.2 \%$ as well as a high percentage of early-stage breast cancer $(68.2 \%)$ and a very low fraction of interval cancers (4.7\%). As expected, the sensitivity of MRI (85.8\%) was significantly higher than the sensitivity of mammographic screening $(49.9 \%)$ ( $p$ value $<0.001)$. The most important finding of the current study is that in the 17 BRCA2 
Table 2 Screening sensitivity according to screening modality and age at diagnosis

\begin{tabular}{llll}
\hline Sensitivity & All breast cancers $n=85$ & $\begin{array}{l}\text { Breast cancers diagnosed } \\
\text { before age } 40 \\
N=17(20.0 \%)\end{array}$ & $\begin{array}{l}\text { Breast cancers diagnosed at } \\
\text { age } \geq 40 \text { years } \\
n=68(80.0 \%)\end{array}$ \\
\hline Combined screening & & & $\begin{array}{l}p \\
(80.0\end{array}$ \\
All breast cancers & $95.2 \%(81 / 85)$ & $94.1 \%(16 / 17)$ & $95.6 \%(65 / 68)$ \\
DCIS & $100 \%(23 / 23)$ & $100 \%(6 / 6)$ & $100 \%(17 / 17)$ \\
Invasive breast cancer & $93.5 \%(58 / 62)$ & $90.1 \%(10 / 11)$ & $94.1 \%(48 / 51)$ \\
MR screening & & & $85.3 \%(58 / 68)$ \\
All breast cancers & $85.8 \%(73 / 85)$ & $88.2 \%(15 / 17)$ & $70.6 \%(12 / 17)$ \\
DCIS & $73.9 \%(17 / 23)$ & $83.3 \%(5 / 6)$ & $90.1 \%(46 / 51)$ \\
Invasive breast cancer & $90.3 \%(56 / 62)$ & $90,9 \%(10 / 11)$ & 1.000 \\
X screening & & $47.1 \%(8 / 17)$ & 1.000 \\
All breast cancers & $49,4 \%(42 / 85)$ & $50.0 \%(3 / 6)$ & $50.0 \%(34 / 68)$ \\
DCIS & $65.2 \%(15 / 23)$ & $45.4 \%(5 / 11)$ & $70.6 \%(12 / 17)$ \\
Invasive breast cancer & $43.5 \%(27 / 62)$ & & $43.1 \%(22 / 51)$ \\
\hline
\end{tabular}

Table 3 Mammography-only detected breast cancers

\begin{tabular}{|c|c|c|c|c|c|}
\hline No & Age at diagnosis & Tumor type & Grade & Size & Nodal status \\
\hline 1 & 57 & $\begin{array}{l}\text { Invasive breast } \\
\text { cancer NST with } \\
\text { EIC * } \\
\text { ER-, PR-, Her2- }\end{array}$ & 2 & $5 \mathrm{~mm}$ & $N-$ \\
\hline 2 & 54 & DCIS & 3 & $10 \mathrm{~mm}$ & $\mathrm{np}$ \\
\hline 3 & 54 & $\begin{array}{l}\text { Invasive breast } \\
\text { cancer NST with } \\
\text { EIC } \\
\text { ER+, PR+, Her2- }\end{array}$ & 3 & $3 \mathrm{~mm}$ & $N-$ \\
\hline 4 & 57 & DCIS & 2 & $6 \mathrm{~mm}$ & $\mathrm{np}$ \\
\hline 5 & 51 & DCIS & 2 & $20 \mathrm{~mm}$ & np \\
\hline 6 & 38 & DCIS* & 3 & $6 \mathrm{~mm}$ & np \\
\hline 7 & 57 & DCIS & 3 & $15 \mathrm{~mm}$ & np \\
\hline 8 & 59 & DCIS* & 2 & $14 \mathrm{~mm}$ & $\mathrm{np}$ \\
\hline
\end{tabular}

NST no special type, EIC extensive intraductal component, $n p$ sentinel node or axillary lymph node dissection not performed

*In retrospect visible on MRI

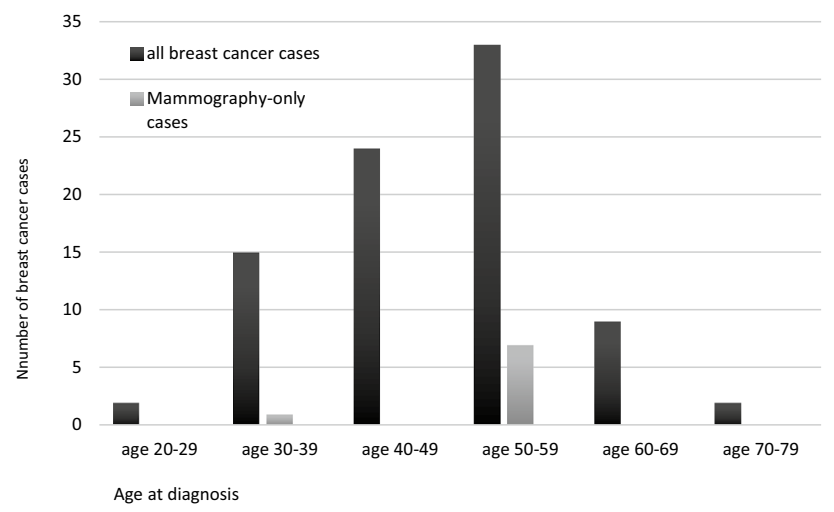

Fig. 1 All breast cancer cases and mammography-only breast cancer cases per 10-year age group mutation carriers diagnosed with breast cancer before age 40 , there was just one mammography-only lesion concerning a $6 \mathrm{~mm}$ DCIS grade 3 in a 38-year-old woman $(5,9 \%$ (1/17)). This lesion was retrospectively visible on MRI and therefore not truly MRI occult. The additional value of mammography is negligibly small in BRCA2 carriers younger than 40 years old.

However, in BRCA2 mutation carriers, aged 50 and older mammographic screening did demonstrate a screening benefit in addition to MR screening. Of the 44 cancers diagnosed above age 50, 7 cancers, concerning predominantly DCIS but also small invasive lesions with an extensive intraductal component, were detected by mammography only, increasing sensitivity in this subgroup from $79.5 \%$ (35/44) to $95.5 \%$ 
$(42 / 44)(p=0.0082)$, indicating that mammography may have supplemental value in this age group.

Strikingly, mammographic screening did not contribute over MRI screening in women diagnose between age 40 and 49 years. The very limited additional value of mammographic screening combined with the increased radiation risks in young mutation carriers $[5,6]$ and the additional burden placed upon patients by supplemental mammography are arguments to postpone the start of mammographic screening to at least age 40 . The lack of screening benefit of mammography over MRI in women between 40 and 49 years of age suggests that mammographic screening might even be postponed to age 50. A prerequisite is that annual MRI screening is performed in a dedicated center.

One could argue that the DCIS cases depicted by mammography-only represent overdiagnosis. However, an argument against overdiagnosis is that all DCIS lesions detected with mammography-only as well as with MRI were grade 2 or grade 3, which seems relevant in this high-risk population. Moreover, it is known that pre-invasive lesions, such as DCIS, are common in BRCA-associated breast cancers [18] and that in high-risk women with DCIS, the prevalence of a BRCA1/2 mutation is high [19]. Yang and colleagues [20] found, in BRCA-associated breast cancers with an invasive and an in situ component, a high concordance of DCIS and invasive phenotypes. These findings may suggest that DCIS, like in sporadic breast cancer, may be considered as a step in the pre-invasive progression pathways in BRCA mutationrelated breast cancers.

Phi et al. [3] conducted a meta-analysis of six high-risk prospective screening studies and reported on 72 BRCA2 breast cancer cases. In contrast to our results, one-third $(6 / 18)$ of breast cancers diagnosed before age 40 years were detected with mammography only. However, in this metaanalysis, the MRI sensitivity was just 50\% (9/18) for the younger age group and $73.6 \%$ (53/72) for all ages. The poor MRI screening results of this meta-analysis can likely be explained by the fact that some of the included studies were multicenter studies starting with breast MRI screening at the beginning of the MRI-era and, therefore, were conducted in centers with little MRI screening experience. MR screening performance has clearly improved since then [2, 4, 21, 22].

The prospective cohort study of the High Risk Ontario Breast Screening Program [23] included, from July 2011 to December 2016, 8782 high-risk women, of which 1885 were BRCA1/2 mutation carriers. In mutation carriers, younger than 40 years of age the sensitivity of MRI alone was comparable to the combination of MRI and mammography (96.8\% vs $100 \%, p$ 0.99). In carriers aged 50-69 years, combining MRI and mammography increased sensitivity compared with MRI alone (92.7\% vs $83.5 \%, p$ 0.02), which seems in line with our findings. However, outcomes were not given for BRCA1 and BRCA2 mutation carriers separately.

Other studies [12, 24-30] presenting screening results in proven BRCA2 mutation carriers had small numbers, varying between 2 and 25 breast cancer cases. The mammographic benefit in these studies was limited, especially in women diagnosed with breast cancer before age 40 . However, the small numbers make it difficult to draw solid conclusions.

Krammer [31] presented the results of 496 BRCA breast cancer cases diagnosed between 1999 and 2013. None of the 211 BRCA 2 breast cancers were identified by mammography only. However, at the time of breast cancer diagnosis, nearly half of the participants had clinical symptoms. Therefore, the outcomes are difficult to compare with ours and that of the above-mentioned studies, but underline the observation that MRI seems to detect most of BRCA2-associated breast cancers.

It should be noted that 2 of 4 interval cancers and 3 of 8 mammography-only cancers were in retrospect visible at the MRI scan, though not recalled. While unfortunate, this finding is not unexpected, and in line with previous studies that retrospectively evaluated MRI scans of patients with breast cancer initially reported to be negative [32-34]. The missed lesions and the higher number of mammography-only lesions in this patient population explain the relatively low MRI sensitivity.

The main limitation of our study is its retrospective design. However, to avoid information bias, the original allocated BIRADS classifications were used. Moreover, we included data from consecutive patient series when possible. Furthermore, although we present a large cohort of BRCA2 breast cancer cases, the sample size is still small. In addition, no information can be provided about the specificity of the screening modalities as we evaluated only breast cancers cases and not a complete screened cohort. However, Vreemann et al. reported a specificity of $84.8 \%$ for first-round MRI examinations in BRCA2 carriers, which steeply increases to $97.4 \%$ in followup rounds, but is still somewhat lower than for mammography (94.4\% and $98.8 \%$, respectively) [35]. Likewise Bick et al. reported, for BRCA2 mutation carriers, a specificity of $85.1 \%$ in first-round examinations and $92.9 \%$ in follow-up examinations using multimodality screening [36]. Further large prospective screening cohorts studies, like the High Risk Ontario Breast Screening Program, are necessary to define the optimal screening protocol for BRCA1 and BRCA2 mutation carriers. 


\section{Conclusions}

Mammographic screening appears to have minimal benefit over MRI screening in BRCA2 mutation carriers younger than 40 years and may not overcome the disadvantages of increased radiation risks.

In BRCA2 mutation carriers of 50 years and older, mammographic screening contributed significantly in the detection of early-stage breast cancer. We propose to omit mammographic screening in young BRCA2 mutation carriers and suggest to postpone mammographic screening in BRCA2 mutation carriers to at least age 40 , or even to age 50 . While the mammography-only lesions were predominantly DCIS one could also consider to perform mammographic screening every two years, starting at age 40 .

Acknowledgements The authors thank M.A.C. Schreurs for her contribution to the statistical analysis.

Author contributions All authors contributed to the study conception and design. Material preparation, data collection, and analysis were performed by I-M Obdeijn, R.M. Mann, and M.J. Hooning. The first draft of the manuscript was written by I-M Obdeijn and all authors commented on previous versions of the manuscript. All authors read and approved the final manuscript.

\section{Compliance with ethical standards}

Conflict of interest The authors declare that they have no conflicts of interest.

Open Access This article is licensed under a Creative Commons Attribution 4.0 International License, which permits use, sharing, adaptation, distribution and reproduction in any medium or format, as long as you give appropriate credit to the original author(s) and the source, provide a link to the Creative Commons licence, and indicate if changes were made. The images or other third party material in this article are included in the article's Creative Commons licence, unless indicated otherwise in a credit line to the material. If material is not included in the article's Creative Commons licence and your intended use is not permitted by statutory regulation or exceeds the permitted use, you will need to obtain permission directly from the copyright holder. To view a copy of this licence, visit http://creativecommons.org/licenses/by/4.0/.

\section{References}

1. Kuchenbaecker KB, Jl H, Barnes DR et al (2017) Risks of Breast, Ovarian, and Contralateral Breast Cancer for BRCA1 and BRCA2 Mutation Carriers. JAMA 317(23):2402-2416. https:// doi.org/10.1001/jama.2017.7112

2. Mann RM, Kuhl CK, Moy L (2019) Contrast-enhanced MRI for breast cancer screening. J Magn Reson Imaging. https://doi. org/10.1002/jmri.26654

3. Phi X-A, Saadatmand S, de Bock GH, Warner E, Sardanelli F, Leach MO, Riedl CC, Hooning M, Mandel R, Santoro F, KwanLim G et al (2016) Contribution of mammography to MRI screening in BRCA mutation carriers by BRCA status and age: individual patient data meta-analysis. BJC 114(6):631-637
4. Obdeijn IM, Winter-Warnars GAO, Mann RM, Hooning MJ, Hunink M, Tilanus-Linthorst MMA (2014) Should we screen BRCA1 mutation carriers only with MRI? A multicenter study. Breast Cancer Res Treat 144(3):577-582. https://doi.org/10.1007/ s10549-014-2888-8

5. Obdeijn IM, Heijnsdijk EAM, Hunink MGM, Tilanus-Linthorst MAM, de Koning HJ (2016) Mammographic screening in BRCA1 mutation carriers postponed until age 40: evaluation of benefits, costs and radiation risks using models. Eur J Cancer 63:135-142

6. Pijpe A, Andrieu N, Easton DF, Kesminiene A, Cardis E, Noguès C, Gauthier-Villars M, Lasset C, Fricker JP, Peock S, Frost D, Evans DG, Eeles RA, Paterson J, Manders P, van Asperen CJ, Ausems MG, Meijers-Heijboer H, Thierry-Chef I, Hauptmann M, Goldgar D, Rookus MA, van Leeuwen FE, on behalf of GENEPSO, EMBRACE, and HEBON (2012) Exposure to diagnostic radiation and risk of breast cancer among carriers of BRCA1/2 mutations: a retrospective cohort study (GENE-RADRISK). BMJ 345:e5660. https://doi.org/10.1136/bmj.e5660

7. Baert A, Depuydt J, Van Maerken T, Poppe B, Malfait F, Storm K, van den Ende J, Van Damme T, De Nobele S, Perletti G, De Leeneer K, Claes KB, Vral A (2016) Increased chromosomal radiosensitivity in asymptomatic carriers of a heterozygous BRCA1 mutation. Breast Cancer Res 18(1):52. https://doi.org/10.1186/ s13058-016-0709-1

8. Baert A, Depuydt J, Van Maerken T, Poppe B, Malfait F, Van Damme T, De Nobele S, Perletti G, De Leeneer K, Claes KB, Vral A (2017) Analysis of chromosomal radiosensitivity of healthy BRCA2 mutation carriers and non-carriers in BRCA families with the G2 micronucleus assay. Oncol Rep 37(3):1379-1386. https:// doi.org/10.3892/or.2017.5407

9. NABON NAtionaal Borstkanker Overleg Nederland. Richtlijn Borstkanker (2018). https://www.oncoline.nl

10. Hamilton LJ, Evans AJ, Wilson ARM, Scott N, Cornford EJ, Pinder SE, Kahn HN, Macmillan RD (2004) Breast imaging findings in women with BRCA1- and BRCA2-associated breast carcinoma. Clin Radiol 59:895-902

11. Murakami W, Tozaki M, Ide Y, Inuzuka M, Hirota Y, Marukami K, Takahama N, Ohgiya Y, Gokan T (2019) The clinical impact of MRI screening for BRCA mutation carriers: the first report in Japan. Breast Cancer. https://doi.org/10.1007/s12282-019-00955 $-6$

12. Vreemann S, van Zelst JCM, Schlooz-Vries MM, Bult P, Hoogerbrugge N, Karssemeijer N, Gubern-Merida A, Mann RM (2018) The added value of mammography in different age-groups of women with and without BRCA mutation screened with MRI. Breast Cancer Res 20(1):84. https://doi.org/10.1186/s1305 8-018-1019-6

13. Pijpe A, Manders P, Brohet RM et al (2010) Physical activity and the risk of breast cancer in BRCA1/2 mutation carriers. Breast Cancer Res Treat 120(1):235-244

14. Preston DL, Mattson A, Holmberg E, Shore R, Hildreth NG, Boice JD (2002) Radiation effects on breast cancer risk: a pooled analysis of eight cohorts. Radiat Res 158(2):220-235

15. Royal HD (2008) Effects of low level radiation. What's new? Semin Nucl Med 38(5):392-402. https://doi.org/10.1053/j.semnu clmed.2008.05.006

16. Mann RM, Cho N, Moy L (2019) Breast MRI: state of the art. Radiology 292(3):520-536. https://doi.org/10.1148/radiol.20191 82947

17. ACR Bi-Rads Atlas (2013) Breast imaging reporting and data system, 5th edn. American College of Radiology, Reston

18. Arun B, Vogel KJ, Lopez A, Hernandez M, Atchley D, Broglio KR, Amos CI, Meric-Bernstam F, Kuerer H, Hortobagyi GN, Albarracin CT (2009) (A8) High prevalence of preinvasive lesions adjacent to BRCA1/2-associated breast cancers. Cancer Prev Res 2(2):22-127. https://doi.org/10.1158/1940-6207.CAPR-08-0050 
19. Bayraktar S, Elsayegh N, Gutierrez Barrera AM, Lin H et al (2012) predictive factors for BRCA1/BRCA2 mutations in women with ductal carcinoma in situ. Cancer 118(6):1515-1522

20. Yang RL, Mick R, Lee K, Graves HL, Nathanson KL, Domchek SM, Kelz RR, Zhang PJ, Czeriecki BJ (2015) DCIS in BRCA1 and BRCA2 mutation carriers: prevalence, phenotype, and expression of oncodrivers C-MET and HER3. J Transl Med 13:335-342

21. Warner E, Causer PA, Wong JW-N, Wright FC, Jong RA, Hill KA, Messner SJ, Yaffe MJ, Narod SA, Plewes DB (2011) Improvement in DCIS detection rates by MRI over time in a high risk breast screening study. Breast J 17:9-17

22. Passaperuma K, Warner E, Causer PA, Hill KA, Messner S, Wong JW, Jong RA, Wright FC, Yaffe MJ, Ramsay EA, Balasingham S, Verity L, Eisen A, Curpen B, Shumak R, Plewes DB, Narod SA (2012) Long-term results of screening with magnetic resonance imaging in women with BRCA mutations. Br J Cancer 107(1):2430. https://doi.org/10.1038/bjc.2012.204

23. Chiarelli AM, Blackmore KM, Muradali D, Done SJ, Maipruz V, Weerasinghe A, Mirea L, Eisen L, Ranabeck L, Warner E (2019) Performance measures of magnetic resonance imaging plus mammography in the High Risk Ontario Breast Screening Program. J Natl Cancer Inst. https://doi.org/10.1093/jnci/djz079

24. Warner E, Plewes DB, Hill KA, Causer PA, Zubovits JT, Jong RA, Cutrara MR, DeBoer G, Yaffe MJ, Messner SJ, Meschino WS, Piron CA, Narod SA (2004) Surveillance of BRCA1 and BRCA2 mutation carriers with magnetic resonance Imaging, ultrasound a, mammography and clinical breast examination. JAMA 292(11):1317-1325

25. Kuhl CK, Schrading S, Leutner CC, Morakkabati-Spitz N, Wardelmann E, Fimmers R, Kuhn W, Schild HH (2005) Mammography, breast ultrasound, and magnetic resonance imaging of women with high familial risk for breast cancer for surveillance. J Clin Oncol 23(33):8469-8476

26. Hagen AI, Kvistad KA, Maehle L, Holmen MM, Aase H, Styr B, Vabo A, Apold J, Skaane P, Moller P (2007) Sensitivity of MRI versus conventional screening in the diagnosis of BRCAassociated breast cancer in a national prospective series. Breast 16(4):367-374

27. Weinstein SP, Localio AR, Conant EF, Rosen M, Thomas KM, Schnall MD (2009) Multimodality screening of high-risk women: a prospective cohort study. J Clin Oncol 27(36):6124-6128

28. Chiarelli AM, Prummel MV, Muradali D, Maipruz V, Horgan M, Carroll JC, Eisen A, Meschino WS, Shumak RS, Warner E, Rabeneck L (2014) Effectiveness of screening with annual Magnetic Resonance Imaging and mammography: results of the initial screen from the Ontario High Risk Breast Cancer Screening Program. J Clin Oncol 32(21):2224-2230
29. Van Zelst JCM, Mus RDM, Woldringh G, Rutten MJCM, Bult P, Vreemann S, De Jong M, Karssemeijer N, Hoogerbrugge N, Mann RM (2017) Surveillance of women with the BRCA1 or BRCA2 mutation by using biannual automated breast US, MR imaging, and mammography. Radiology 285(2):376-388

30. Lo G, Scaranelo AM, Aboras H, Ghai S, Kulkarni S, Fleming R, Bukhanov K, Crystal P (2017) Evaluation of the utility of screening mammography for high-risk women undergoing screening breast MR imaging. Radiology 285(1):36-43

31. Krammer J, Pinker-Domenig K, Robson ME, Gonen M, BernardDavila B, Morris EA, Mangino DA, Jochelson MS (2017) Breast cancer detection and tumor characteristics in BRCA1 and BRCA2 mutation carriers. Breast Cancer Res Treat 163:565-571

32. Pages EB, Millet I, Hoa D et al (2012) Undiagnosed breast cancer at MR imaging: analysis of causes. Radiology 264:40-50

33. Yamaguchi K, Schacht D, Newstead GM et al (2013) Breast cancer detected on an incident (second or subsequent) round of screening MRI: MRI features of false-negative cases. AJR Am J Roentgenol 201:1155-1163

34. Vreemann S, Gubern-Merida A, Lardenoije S, Bult P, Karssemeijer N, Pinker K, Mann RM (2018) The frequency of missed breast cancers in women participating in a high-risk MRI screening program. Breast Cancer Res Treat 169(2):323-331. https:// doi.org/10.1007/s10549-018-4688-Z

35. Vreemann S, Gubern-Merida A, Schlooz-Vries MS, Bult P, van Gils CH, Hoogerbrugge N, Karssemeijer N, Mann RM (2018) Influence of risk category and screening round on the performance of an MR imaging and mammography screening program in carriers of the BRCA mutation and other women at increased risk. Radiology 286(20):443-451. https://doi.org/10.1148/radiol.20171 70458

36. Bick U, Engel C, Krug B, Heindel W, Fallenberg EM, Rhiem K, Maintz D, Golatta M, Speiser D, Rjosk-Dendorfer D, LammerSkarke I, Dietzel F, Schafer KWF, Leinert E, Weigel S, Sauer S, Pertchy S, Hofmockel T, Hagert-Winkler A, Kast K, Quante A, Meindl A, Kiecjle M, Loeffler M, Schmutzler RK, on behalf of the German Consortium for Hereditary Breast, and Ovarian Cancer (GC-HBOC) (2019) Breast Cancer Res Treat. https://doi. org/10.1007/s10549-019-05152-9

Publisher's Note Springer Nature remains neutral with regard to jurisdictional claims in published maps and institutional affiliations. 